\title{
Focus on psychiatry in Japan
}

\author{
KENJI J. TSUCHIYA and NORI TAKEI
}

Recent reports on deinstitutionalisation in Western countries suggest that a reduction in the number of beds reserved for inpatients may have caused an increase in the need for psychiatric services, particularly among people with schizophrenia (Tsuchiya \& Munk-Jørgensen, 2002). The lessons learned from the consequences of deinstitutionalisation need to be considered in countries in which 'social' admission prevails and where mental health care systems are being reformed; this is especially the case when considering the long-term hospitalisation of mentally ill individuals who might otherwise live in the local community.

Japan's Mental Health and Welfare Law 1995 has been translated into English by Shiraishi et al (2000) and we have used the terminology of that translation in this paper.

\section{MENTAL HEALTH CARE IN JAPAN: AN OVERVIEW}

\section{Psychiatric hospitals}

After the Mental Hygiene Law was enacted in 1950, the total number of beds reserved for psychiatric patients in Japan began a four-decade increase. The number of psychiatric beds per 10000 population was 10.1 in 1960, 24.9 in 1975 and peaked at 29.0 in 1990. The enactment of the Mental Health Law in 1988 (reformed as the Mental Health and Welfare Law in 1995) had the effect, within a few years, of stopping this trend. The number of psychiatric beds levelled off in the 1990s and then dipped to 27.5 per 10000 population in 2000; the total number of psychiatric beds in Japan was 348966 for a population of 126926000 (Ministry of Health, Labour and Welfare, 2002). This figure is still approximately three times higher than the 10 psychiatric beds per 10000 population in the UK in 1998 (Organization for Economic Cooperation and Development, 2002). It is of note that the geographical distribution of psychiatric beds in Japan is not homogeneous. Among Japan's 47 prefectures, the distribution is highest (56.7/ $10000)$ in Kagoshima and lowest (18.3) in Saitama. The overall pattern of regional differences suggests that the figure is higher in the western prefectures and lower in the eastern and northern prefectures.

The 348966 psychiatric beds reserved for psychiatric in-patients in 2000 were held by 1667 hospitals; only 332 (20\%) of these were public-sector hospitals. The Mental Health and Welfare Law 1995 mandated that each of the 47 prefectures should establish at least one public-sector hospital. Of the 1667 hospitals with psychiatric beds, $65 \%$ (1079 hospitals) have exclusively psychiatric beds, most of which are in private hospitals (Ministry of Health, Labour and Welfare, 2002). Thus, a substantial part of hospital care is maintained by private-sector institutions with only psychiatric beds.

\section{In-patients in psychiatric hospitals}

Among the psychiatric beds available, 333003 (95\%) were occupied on 30 June 2000. Fifty-four per cent of the in-patients were male. More importantly, about onethird $(34 \%)$ of the in-patients were aged 65 years or over, and two-thirds $(62 \%)$ were diagnosed with schizophrenia.

Length of stay can be calculated as: $365 \times$ the average number of in-patients per day $(0.5 \times$ the total number of admissions and discharges during a given year). By this calculation, the average length of stay was estimated to be 533 days in 1988, 490 in 1990, 455 in 1995, and 377 in 2000 (Ministry of Health, Labour and Welfare, 2002). This method of calculation, although in official use in Japan, has been criticised because it is likely to reflect biased estimates. Thus, international comparisons should be made with caution. Although excessive stays have been a focus of criticism of psychiatric care in Japan, the average length of stay has decreased more sharply than the number of psychiatric beds.
It is also of note that the length of stay varies from patient to patient. Indeed, of all new patients admitted to a psychiatric bed in June 1999 ( $n=26889$ ), 54\% had been discharged by the end of August 1999 and $15 \%$ remained in the hospital at the end of a 1-year follow-up study.

\section{Hospital staffing levels}

A recent survey revealed that for every 100 psychiatric beds, the following staff statistics apply: 2.7 physicians (psychiatrists), 29.0 nurses, 1.1 social workers, 0.9 occupational therapists, and 0.4 clinical psychologists (Ministry of Health, Labour and Welfare, 2002). The staffing shortage is marked; in particular, the number of clinical psychologists is far lower than would be desirable. Although the number of full-time psychiatrists working at psychiatric facilities, including private hospitals, was about 11500 in 2000 (9.4/100000 population) and this number is viewed as relatively high by international comparison, the overall tendency is for public and university hospitals to employ more staff members and for private hospitals to employ fewer. In fact, Article 21 of the Medical Law, which was reformed in 2001, allows a lower minimum number of psychiatrists to staff hospitals with exclusively psychiatric beds (48 beds per psychiatrist) relative to that of physicians, including psychiatrists, in general hospitals (16 beds per physician). For instance, three psychiatrists suffice for a psychiatric hospital with 156 beds, and only six are required for 300 beds. In addition to the insufficient control over mental health policy, the preference for a workplace in urban areas, especially among young doctors, may have further aggravated the situation of mental health staffing in private psychiatric hospitals located in suburban and rural areas.

In Japan, physicians, nurses, social workers and occupational therapists are licensed by the Ministry of Health, Labour and Welfare, but this is not the case for clinical psychologists, who are licensed by the Japanese Certification Board for Clinical Psychologists under the auspices of the Ministry of Education, Culture, Sports, Science and Technology. The presence of dual authorities that independently influence the mental health care system for health service users may appear cumbersome. The present long-standing situation is a matter of bureaucracy and it does appear to hinder efficient cooperation 
among mental health professionals at a practical level. More mental health workers need to be allocated to fulfil both in-patient and out-patient demands. Primary care in the community is not closely connected with specialised care as a whole; discharged patients are, in general, followed up by staff at the institution that discharged them. This situation arose from a poorly organised referral system and seems to burden hospital staff in terms of the assignment of the direct provision of care. The resultant excessive case-loads are reflected in the following anonymous comment: 'Patients have to wait an hour prior to seeing, and are given only 3 minutes with, a doctor at the out-patient unit of a psychiatric hospital'. Paternalistic care, given mainly by psychiatrists, still prevails in Japan, and also requires reconsideration. In an era of modern psychiatry, service consumers should receive optimal treatment delivered by a well-organised team of specialists with diverse expertise. To provide more efficient and better care for those with a mental illness, Japan needs to integrate work forces as well as attain an adequate allocation of mental health professionals across the country.

\section{Psychiatric clinics for out-patients}

As mentioned above, therapeutic management after discharge is usually maintained by the hospital to which the patient was admitted. However, care provided by psychiatric hospitals, including services for out-patients, is insufficient to meet the high demand for mental health care. This demand is attributable, at least in part, to the lower threshold for consulting a psychiatrist and increased public concern about mental health under the stressful life circumstances experienced in modern society. In fact, there is an increasing number of private psychiatric clinics without beds across the nation (about 3600 in 2000; Ministry of Health, Labour and Welfare, 2002). This increase may partly reflect the shift from custodial care to community care.

\section{Facilities for day care and night care}

There were 1248 facilities offering psychiatric day care and night care across the nation on 30 June 2000 (Ministry of Health, Labour and Welfare, 2002). The total number of registered users of these facilities was 52875 on that date. Of the 1248 facilities, 911 (73\%) were attached to psychiatric hospitals and $311(25 \%)$ to out-patient clinics. Conforming with the regional discrepancy in numbers of hospital beds, psychiatric day and night care facilities are also disproportionately distributed across the country. This is due to initiatives taken by individual hospitals rather than to any government mandate.

\section{Community care and social resources}

A total of 592 local health centres, founded by each of the 47 prefectures in Japan, are the primary providers of mental health care within communities. In addition, the Mental Health and Welfare Law states that each prefecture should establish at least one centre that specialises in mental health and welfare to support local health centres and related organisations and to promote community mental health services. There were 59 mental health and welfare centres in 2001. Of concern in this regard is the closing of local health centres owing to changes in the governance of the centres from prefectures to local municipalities.

Accordingly, a fundamental problem is the relative lack of social resources for mentally ill individuals. This led the national government in 1995 to found the Seven-year Strategy of Normalisation for the Disabled. Its goal was to shift 20000 30000 of Japan's 330000 (in 1995) psychiatric in-patients to community care within 7 years. Consequently, the number of facilities for the promotion of community care, such as those offering residence and those providing opportunities for improving patients' living and working skills, was boosted; however, the goals of the strategy have been only partially fulfilled to date. In effect, the increase in the number of facilities has not been significantly reflected by a decrease in the number of psychiatric in-patients. Without doubt, the shortage of social resources in the community is one reason why many patients have experienced unnecessarily long stays in hospitals.

\section{Medical assistance for psychiatric treatment}

All residents of Japan are basically insured by the national health care system. Semigovernmental insurance organisations typically cover up to $70 \%$ of the cost of the services received by an individual, who in general is responsible for the remaining $30 \%$. However, there are some exceptions to this rule: children, the elderly and people with physical disabilities, specific chronic illnesses or mental illness may be exempt from payment, depending on the severity of the illness and the local health policy. Article 30 of the Mental Health and Welfare Law assures that the involuntary admission of an individual, ordered by the governor of the prefecture on the grounds of imminent risk of suicide and/or harming others, as judged by psychiatrists under Article 29, is free of charge. On 30 June 2002 a total of 3247 (1\%) of all 333003 in-patients were hospitalised under this article (Ministry of Health, Labour and Welfare, 2002). Furthermore, Article 32 of the Mental Health and Welfare Law requires that local authorities pay a psychiatric facility the remaining cost of each visit to its out-patient clinic by a patient with severe mental illness that is not covered by insurance organisations. However, this financial support is not mandatory and is provided only for patients who apply for such aid.

Despite Japan's universal health insurance coverage, there is no strict regulation of referral to physicians, as mentioned above. Basically, an individual who wishes to see a doctor can freely choose any doctor, with the choice ranging from a local practitioner to a highly specialised physician at a university hospital. There is only one exception: a major hospital may require an individual to obtain a letter of referral from an attending physician. If the individual does not obtain such a letter, he or she must pay an extra fee. This restrictive rule has recently been introduced to encourage patients to receive primary medical care from local practitioners, since health care users in Japan have, understandably, preferred visiting large and renowned hospitals.

\section{How to become a psychiatrist and a 'designated psychiatrist'}

For medical students, a minimum 6-year period of education and training at medical schools, including universities and medical colleges, is required. This includes 1 year of ward training. Postgraduate medical students are then qualified to take the National Examination for Physicians (NEP). Those who pass the NEP are eligible to take a 2-year postgraduate training course offered by teaching hospitals, usually university hospitals, public hospitals or regional major hospitals. However, postgraduate training in psychiatry, as well as in other medical specialties, is arbitrary 
at the moment, and the selection of teaching hospitals is made entirely by the candidates and not by the hospitals; that is, this system requires neither rigid examinations nor official interviews. During the first year of postgraduate psychiatric training, a majority of young physicians typically belong to and are under the supervision of a department of psychiatry at a university hospital. A 2-year postgraduate training will become obligatory as a planned introduction of internship beginning in 2004. This new development has arisen from the perspective that the basic medical and practical skills of postgraduate physicians need to be improved.

In the current system, any physician can legitimately claim that he or she is a psychiatrist after passing the NEP examination. On the other hand, from both a practical and an ethical point of view, the Menta Health and Welfare Law authorises some psychiatrists (referred to as seishin hoken shitei-i, designated psychiatrists) to conduct psychiatric assessments in relation to legal procedures such as involuntary admission and restrictions of a patient's freedom. To achieve such a designation, a psychiatrist must have at least 5 years of clinical experience, including at least 3 years of training in clinical psychiatry. In addition, he or she must attend a 2-day course prepared by experienced psychiatrists that covers legal, ethical and clinical issues. Then, applicants are required to submit eight case reports to the National Ministry of Health, Labour and Welfare. These cases must involve major psychiatric illnesses such as schizophrenia, affective disorders, substancerelated disorders, senile dementia, organic mental disorders, and child and adolescent disorders. Qualification is judged purely on the merits of the report; nearly one-third of applicants fail to qualify. Except for a mandatory 1-day course for extending qualification for an additional 5 years, no other systematic training for psychiatrists exists in Japan.

\section{Research activities}

About $3-4 \%$ of papers that appear in the high-ranked peer review journals in the life sciences field are from Japan, but the corresponding proportion is far lower in respectable clinical journals (Fukui, 1999). Low numbers of clinical studies are also the case in the field of psychiatric research. For example, a Medline survey showed that the number of papers on schizophrenia per psychiatrist in Japan is very low in an international comparison of non-Englishspeaking countries (Takei \& Verdoux, 1997). The low activity in this regard may be partly due to relatively poor funding of clinical research in mental health and psychiatry in Japan (Takei, 1996).

\section{PSYCHIATRY IN JAPAN: SPECIFIC ISSUES}

In general, it appears that mental health care in Japan has improved, in part in terms of a shift from custodial to community care as a response to great domestic and international concern that accumulated around 1990. However, some specialty areas have remained relatively untouched until recently. These include forensic psychiatry, child and adolescent psychiatry, substance misuse and changes in the naming of psychiatric disorders.

\section{Reconsideration of forensic psychiatry}

Recently, a dreadful homicide took place in the Osaka Prefecture. According to the newspapers, a 37-year-old man, armed with a knife, rushed into a classroom at the Ikeda primary school on 8 June 2001, and slaughtered 8 children while injuring 15 , including teachers. The suspect had a lengthy criminal history beginning in late adolescence, with crimes including rape, injury, attempted housebreaking and attempted murder. He had been sentenced to, and completed, a 3-year term for the rape, but was never prosecuted for the other incidents. The newspapers also reported that he had had a history of psychiatric treatment since his early $20 \mathrm{~s}$, including several hospital admissions. In April 1999, the suspect attempted to murder his colleagues by lacing their drinks with psychotropic drugs, which necessitated his involuntary admission to a psychiatric hospital. His diagnosis at the time of admission was not reported, but a pre-trial psychiatric examination convinced public prosecutors that he was able to take full responsibility for his criminal actions at the time of the Ikeda primary school incident (The Asabi Shimbun, 2001).

The official statistics revealed that 2072 criminal cases related to possible mental illness were dealt with by the police in 2000 , accounting for about $0.7 \%$ of the total number of criminal cases (National Police Agency, 2001). Almost all of these patients were committed to the mental health system under the Mental Health and Welfare Law, because the crimes they had perpetrated were considered to be inherent to their mental illness. Among the 2072 cases, 1337 (65\%) were not sent to public prosecutors, but were instead transferred from the police to psychiatric care in accordance with Article 24 of the Mental Health and Welfare Law. Most of these patients were severely ill, and their need for treatment was clear. The remaining 735 cases $(35 \%)$ were sent to public prosecutors. Of these cases, $651(89 \%)$ were not prosecuted, and only the remaining $84(11 \%)$ were prosecuted and dealt with by the courts: each of these individuals received a sentence mitigated on the grounds of mental illness. Of the 651 mentally ill offenders who were not prosecuted, 573 (as well as 2 of the 84 offenders transferred to the courts) were ordered to be hospitalised (mostly by involuntary admission) under the Mental Health and Welfare Law.

The Ikeda primary school incident raised serious public concern, and the following accusation was often heard: 'Why was the suspect not prosecuted for criminal acts, and why was he admitted to a psychiatric hospital with no special legal provision?'

Whether or not a case should be prosecuted in Japan is totally at the discretion of the public prosecutors, which may account for the striking differences between the number of cases handled by police, by prosecutors and by the courts. Mentally ill offenders may be expelled from the criminal justice system to the mental health system, often at a very early stage. The manner in which forensic cases were handled in Japan had been criticised long before the Ikeda incident occurred, not only because this approach deprived the suspects of the chance to stand trial (Nakatani, 2000), but also because it neglected the prevention of recidivism. Moreover, the rate of recidivism among individuals who were not prosecuted because of mental disorders has been reported to be about $30 \%$ (Igarashi, 2002).

Japan has no specific legal provisions for mentally ill criminal offenders in clinical settings (Nakatani, 2000). There are no judicial rules that intervene in the imposition of psychiatric treatment: once mentally ill offenders are entrusted to the mental health system, they are treated in accordance with the procedures of the Mental Health and Welfare Law, with no influence from the criminal justice system. Consequently, 
offenders with a mental disorder are treated as mentally ill non-offenders in ordinary psychiatric hospitals, where there are no specially trained staff or isolated wards for mentally ill offenders. Discharges are determined solely on a medical basis, not on a legal basis, and there are no mandatory probation schemes to provide for necessary maintenance therapy after discharge, nor standard measures to preclude the recurrence of criminal actions.

The day after the Ikeda incident, Japan's Prime Minister, Jun-ichiro Koizumi, stated that the 'imperfection of the law has become clear, and certain changes to Japan's psychiatric treatment system should be considered for mentally ill offenders'. On 18 March 2002, the ruling Liberal Democratic Party proposed a new policy for the treatment of people with a mental illness which included the establishment of forensic wards in public sector hospitals. After long deliberation in the Diet, the proposal was passed on 6 June 2003.

In addition, there is no national system in Japan for the education of psychiatrists in the specialty of forensic psychiatry. Very few university departments and medical colleges even offer such a specialty.

\section{Child and adolescent psychiatry}

The most fundamental problem in child and adolescent psychiatry is the inadequate provision of mental health care for children and adolescents. In the late 1990s, throughout Japan only about 100 physicians specialised in child and adolescent psychiatry (Yamazaki, 1999), corresponding to about 1 per million people. One reason for this lack is the limited number of beds available for young people: in 2000 , there were only 718 such beds, $0.2 \%$ of the total number of beds in psychiatric hospitals (Ministry of Health, Labour and Welfare, 2002). About $2 \%$ of the total time that medical students spend on psychiatry is allocated to child and adolescent psychiatry. Until recently, virtually no independent department for child and adolescent psychiatry existed in medical schools in Japan. Nagoya University, which has one of the longest histories of providing psychiatric services for children and adolescents in the country, established an independent department of child and adolescent psychiatry in 2001.

Despite such a near-total absence of services, public concern about the provision of psychiatric care for children and adolescents did not emerge until the end of the 1990s. The situation changed after three consecutive brutal events caused by three adolescents shocked the nation. In May 2000, according to the newspapers, a 17-year-old high-school student hijacked a bus in the western part of Japan. The passengers were kept hostage inside the bus, and the boy killed one passenger and injured four with a knife. When he was arrested, he told prosecutors that he had simply wanted to kill somebody. One month later, another 17-year-old boy used a baseball bat to inflict severe injuries on four of his friends and to beat his mother to death. Then, in December, another 17-year-old boy attempted to kill a family of six with a knife. Three died and three were severely injured. Later, the youth reported that his motive was the fear that the victims would report his past misconduct to the police.

These incidents have aroused public concern that children and adolescents are currently prone to bouts of rage (kireyasui) and irritability towards others without a particular reason (mukatsuku). The presence of such a sociopathological behavioural pattern among adolescents is also supported by a recent survey of 3000 children aged 9-14 years (Cabinet Office, 2001), which showed that $49 \%$ of them did not feel self-confident and $27 \%$ thought of themselves as incapable; in addition, $36 \%$ had a tendency towards irritability and $30 \%$ tended to use violence when they were extremely angry.

Other important aspects of sociopathology among young people in Japan include ijime (continuous psychological and/ or violent harm to an individual, usually by a group of other individuals; bullying), which has been of particular concern for the past two decades among younger schoolchildren and adolescents. The incidence of ijime reported in state schools was 150000 in 1985 , but only 30000 , or 0.8 events per school, in 1999 (Cabinet Office, 2001). However, the more recent presentation of ijime is not limited to school, as it was in the 1980s; hence, many hidden incidents of this form of abuse are quite likely to occur. Indeed, the number of suicides by children and adolescents, which is in part thought to be related to ijime, slightly increased in the 1990s. The ageadjusted suicide rate of children aged 10-14 per the corresponding 100000 population was 0.6 in 1990 and 1.1 in 2000; and for ages $15-19$, it was 3.8 in 1990 and 6.4 in 2000.

\section{Substance misuse}

Among the 333003 in-patients at hospital on 30 June 2000, $17572(5.3 \%)$ had a diagnosis of alcoholism (ICD-10), 878 $(0.2 \%)$ methamphetamine misuse and/or methamphetamine-induced psychosis, and $1574(0.5 \%)$ other substance-related disorders (Ministry of Health, Labour and Welfare, 2002). Although the hidden number of substance misusers is not precisely known, such misuse is a major social problem. Alcohol consumption per capita grew rapidly between 1965 and 1985 (from 5.861/year to 8.591/year), but has since then decreased slightly $(8.301 /$ year in 1999). Nevertheless, the number of frequent drinkers has been increasing, particularly among adolescents. Recent assessments show that the proportion of frequent drinkers among male 7 th-grade students (aged $12-13$ years) is $12 \%$, and the rate is $10 \%$ among female 7 th-grade students. The proportion is much higher among 12th-grade male and female students ( $35 \%$ and $29 \%$, respectively). Such high proportions among young people are probably related to the wide availability of alcohol vending machines across the nation.

The drugs of choice among adolescents in Japan are different from those in Western countries. Methamphetamine use is the most serious type of drug misuse in connection with mental illness. The first wave of prevailing use came in the early 1950s (60000 arrests/year), the second wave occurred in the early 1980s (25000 arrests/year) and in the 1990s, the third wave arrived $(20000$ arrests/year). The distributors of methamphetamine are thought to be Yakuza, the Japanese mafia. Methamphetamine psychosis is a clinical diagnosis founded in psychiatric practice in Japan, and its pathophysiological mechanism is considered to differ from that of schizophrenia (Iwanami et al, 1994).

Other drugs of choice include inhalants, mostly paint thinner and toluene. A recent survey reported that $3.4 \%$ of a random population of 5000 had been tempted to use thinner (Ozaki \& Wada, 2001). This estimate tops the list of other drugs used, followed by cannabinoids at $1.8 \%$ and methamphetamine at $1.0 \%$. The most important features of inhalant use are that it typically begins at a very early age (among frequent users, the average age at first use is 16.0 years) and that it is related strongly to adolescent delinquency and to the use of other illicit drugs, especially methamphetamine. 


\section{Psychotherapies established in Japan}

Although mainstream psychotherapy in Japan is derived from the frameworks of Western psychotherapy, two methods of psychotherapy were established in Japan, namely, Morita therapy (Kitanishi \& Mori, 1995) and Naikan therapy (Kawahara, 2001). These two therapies differ in particular from psychoanalytic methods in that both have a basis in Japanese culture including an indirect influence from Eastern Buddhist religions; therapists employing these therapies do not deal with resistance and transference in an interpretative manner (Murase \& Johnson, 1974).

Owing to space limitations, we describe only Morita therapy here. It was founded in 1919 by Masatake Morita (1874-1938). It features a therapeutic framework including bed-rest and work, principally aimed at Morita shinkeishitsu, which Morita indicated is the morbid status formed in those with both predisposition and hypochondriacal attributes who encounter an invoking situation. The therapy was originally provided on an admission-only basis, although the method was later modified to include out-patient treatment. With the surge of cognitive-behavioural therapy in the treatment of mental illnesses in the West, Morita therapy has been reconsidered for its usefulness because the process of the therapy inherently incorporates aspects of rectifying and unleashing distorted cognitions held by patients, who are encouraged to cope with problems by taking particular action. However, this treatment is available in only a limited number of facilities. Kitanishi \& Mori (1995) reviewed the effectiveness of the treatment, demonstrating fair results not only among those with typical Morita shinkeishitsu, but also among patients with disorders within the same spectrum, including obsessive-compulsive disorder. It is unfortunate that, to our knowledge, no controlled studies have explored the effectiveness of this therapy in individuals with psychiatric diagnoses.

\section{New terminology for schizophrenia}

Recently, the Japanese Society of Psychiatry and Neurology (JSPN) proposed changing the term schizophrenia to togo shitchosho, the literal meaning of which is 'dysfunction of integration' (Japanese Society of Psychiatry and Neurology, 2002; see also Kim \& Berrios, 2001). The committees of the JSPN explained that the change was needed to reduce stigmatisation against individuals with schizophrenia. Unlike in English, most morphemes of written Japanese words convey a straightforward meaning on their own. In English, on the other hand, the original meaning of a word is often quite foreign, even to native speakers (e.g. the 'phren-' of 'schizophrenia' is from the Greek, meaning 'breath' or 'soul'). The formerly used written term in Japanese for schizophrenia, seishin bunretsubyo, explicitly indicates 'mind-split disease'. Individuals with schizophrenia can be easily stigmatised (Kim \& Berrios, 2001), and this problem prompted Zenkaren, the National Federation of Families of Mentally Ill Individuals in Japan, to ask the JSPN in 1993 to adopt a less stigmatising or more neutral term. After a prolonged discussion within the JSPN, the organisation ultimately decided to change the term.

\section{CONCLUSIONS}

By and large, until the early 1990s in Japan, only overcrowded custodial care in a hospital setting was available for patients with mental illness. However, the enactment of the Mental Health Law in 1988 and of the Mental Health and Welfare Law in 1995 appears to have successfully exerted some of the desired effects on admission policies, for example by causing a shift from inpatient care to community-based care. That shift is ongoing, but further improvement remains necessary, not only in psychiatric custodial and community care, but also in the specialised field of medical psychiatry. Research should be supported more than ever and the results of new studies should be applied in order to enact improved mental health policies in the near future.

\section{ACKNOWLEDGEMENTS}

The authors thank the following people for their helpful comments: Dr Shigeru Masuko (Chief Consultant) and Dr Kazutoshi Kawaseki (Director) of the Tokyo MetropolitanTama Center for Mental Health; Professor Ryuzo Kawahara, Department of Psychiatry, Tottori University; Dr Yoshiharu Kim, Department of Adult Mental Health, National Institute of Mental Health in Japan; and Dr Hiromi Shiraishi, Department of Mental Health Services, Psychiatric Research Institute of Tokyo. N.T. thanks the Stanley Medical Research Institute for financial support.

\section{REFERENCES}

Asahi Shimbun, The (200I) Editorial: Psychiatric examination system needs major review. 17 September 200I. http://www.asahi.com/english/op-ed/ K2001091800557.htm

Cabinet Office (200I) Child and Adolescent Statistics [in Japanese]. Tokyo: Printing Bureau, Ministry of Finance.
Fukui, T. (1999) Evidence-based medicine and medical practices for individuals [in Japanese]. Nikkei Medical, May (suppl. 6), 5-6.

Igarashi, Y. (2002) Treatment of mentally ill offenders and problems underlying forensic psychiatry in Japan [in Japanese]. Gendai Keijiho, 40, 5I-63.

Iwanami, A., Sugiyama, A., Kuroki, N., et al (1994) Patients with methamphetamine psychosis admitted to a psychiatric hospital in Japan. A preliminary report. Acta Psychiatrica Scandinavica, 89, 428-432.

Japanese Society of Psychiatry and Neurology (2002) Symposium: Beyond the term 'schizophrenia' [in Japanese]. http: //www.jspn.or.jp//Isitsu.html

Kawahara, R. (200I) The Japanese Pure Land (Jodo) concept of Buddhism and Naikan (introspection) therapy [in Japanese]. Seishin Shinkeigaku Zasshi, 103,959-966.

Kim, Y. \& Berrios, G. E. (200I) Impact of the term schizophrenia on the culture of ideograph: the Japanese experience. Schizophrenia Bulletin, 27, |8|-|85.

Kitanishi, K. \& Mori, A. (1995) Morita therapy: 1919 to 1995. Psychiatry and Clinical Neuroscience, 49, 245-254.

Ministry of Health, Labour and Welfare (2002) Data on Mental Health and Welfare [in Japanese]. Ichikawa: National Institute of Mental Health in Japan.

Murase, T. \& Johnson, F. (1974) Naikan, Morita, and Western psychotherapy. Archives of General Psychiatry, 3I, $121-128$.

Nakatani, Y. (2000) Psychiatry and the law in Japan. History and current topics. International journal of Law and Psychiatry, 23, 589-604.

National Police Agency (200I) Police Statistics [in Japanese]. Tokyo: Printing Bureau, Ministry of Finance

Organization for Economic Cooperation and Development (2002) OECD Health Data 2002. Paris: OECD.

Ozaki, S. \& Wada, K. (200I) A nationwide survey on drug related psychiatric illness in the psychiatric facilities. In An Epidemiologic Study of Drug Abuse and Dependence and a Study of Appropriate Medical Services to Patients with Substance Related Psychiatric Disorders [in Japanese] (ed. K.Wada), pp.77-1I8. Ichikawa: National Institute of Mental Health in Japan.

Shiraishi, H., Igarashi, Y., Ikehara, T., et al (2000) LaW Related to Mental Health and Welfare of the Person with Mental Disorder. http: / /www. prit.go.jp/Ja/Mhser/ hokenhou.pdf

Takei, N. (1996) Funding of research in mental health care in Japan. Lancet, 347, 523-524.

Takei, N. \& Verdoux, H. (1997) Research activities on schizophrenia in 17 non-English speaking countries: a Medline survey. European Psychiatry, 12, 319-320.

Tsuchiya, K. J. \& Munk-Jørgensen, P. (2002) Firstadmission rates of schizophrenia in Denmark, 19801997: have they been increasing? Schizophrenia Research, 54, 187-191.

Yamazaki, K. (1999) Child and adolescent psychiatry in university hospital in Japan: present situation and problems [in Japanese]. Seishin Igaku (Clinical Psychiatry), 41, 1262-1269.

Kenji J.Tsuchiya Tokyo Metropolitan Tama Center for Mental Health and Department of Psychiatry and Neuroscience, Tokyo Medical and Dental University, Japan

Nori Takei Departmentof Psychiatryand Neurology, Hamamatsu University School of Medicine, I-20-IHandayama, Hamamatsu 43I-3192,Japan (tel: +8I 534352295; fax: +81534353621; e-mail: ntakei@hama-med.ac.jp), Stanley Foundation Research Centre,Japan, and Institute of Psychiatry, London,UK 